\title{
STATUS OF INDIAN WILD ASS (EQUUS HEMIONUS KHUR) IN THE LITTLE RANN OF KUTCH
}

\author{
H.S. Singh \\ Director, GEER Foundation, Indroda Park, Gandhinagar, Gujarat 382009, India
}

\begin{abstract}
The Indian Wild Ass, Equus hemionus khur is found restricted to the Rann of Kutch in Gujarat and its surrounding areas. The population of the sub species is on the increase in the ninetees since the last debilitating effects of the drought in 1987. The numbers are slowly increasing to the carrying capacity of the area, towards the recommended numbers suggested in the IUCN Action Plan. The numbers of Wild Ass may reach 4000 by 2010AD, if current conditions prevail and there is no severe setback by droughts. However, the study on the status of the Wild Assess indicates that the increasing numbers may cause problems to the local inhabitants. The threats by the loss of habitat due to exotic plants, salt manufacturing activities, defence activites and cattle grazing may affect the population, which is also likely to get dispersed in the coming years to the adjacent Thar Desert areas in Rajasthan. The paper discusses the population trends of the WIld Ass over the years and its effects, as also the need for alternate measures of conservation.
\end{abstract}

\section{Key words}

Indian Wild Ass, population, distribution, status, migration, conservation, Wild Ass Sanctuary

\section{Introduction}

The Little Rann of Kutch in Gujarat State in India is a unique saline desert and is synonymous with the Indian Wild Ass (Equus hemionus khur). The Wild Ass, a handsome beast called ghodkhad or ghorkhar is the main attraction of the area. To conserve this animal, an area of 4954 sq.km. in the Little Rann, its fringe areas and some Bets (upland or island) in the Great Rann of Kutch were declared as the Wild Ass Sanctuary in 1973. Kutch, Banaskantha, Mehsana, Surendranagar, and Rajkot districts and Gulf of Kutch constitute boundaries of the Sanctuary. Recognising its uniqueness and ecological significance, the area has been listed by the Government of India (GOI) as among the first 13 areas selected for conservation as Biosphere Reserve, which is pending with the state government for finalizing the declaration (Khacher, 1994).

\section{Methods}

The GEER Foundation conducted a comprehensive ecological study in the Wild Ass Sanctuary from November, 1997 to March, 1999. This paper is primarily based on the analysis of the field

Received 5 July 1999;
Accepted 29 February 2000 data collected during the period. The Rann, fringe area, Bets of the Sanctuary and Khadir Bet were surveyed during the study. Remote sensing study was done to know the vegetation cover classes and the habitat conditions.

To study the Wild Ass in the Sanctuary, the entire area was divided into three regions and seven zones - southern fringe, eastern fringe, northern fringe, western fringe, creeks, Bets and a part of the Sanctuary in the Great Rann. People in the villages were requested to collect relevant information about the Wild Ass. Total counting of Wild Ass was done in November, 1998 by a team of investigators in and around the Little Rann, which was completed in 18 days. Surveys were also carried out in the Great Rann and other areas inhabited by the Wild Ass to estimate dispersed population. Data collected during Wild Ass census conducted by the Forest Department on 28 and 29 January, 1999 was also used for analysis.

Wild Asses were counted during rainy season in 1998 on some of the important Bets to study the breeding area. Pung, Dhut, Nanda, Shedwa, Mardak, Fatehgadh, Nada, Khadir and other Bets in the Great Rann were extensively surveyed in November and December, 1998. Observations were made up to the border 
of Rajasthan and Pakistan. Field investigators made regular entry in a register with all details such as date, time, site, group composition, activity, habitat etc.

\section{Results and discussion}

Out of 68 species of mammals in the Indian Desert, 61 species of mammals are recorded in Gujarat portion of the Indian Desert and majority of them occur in the Rann (Alfred \& Agrawal, 1996). This study recorded 33 species of mammals, which do not include the entire list of rodents and bats. Nine species of mammals in the Rann are listed in the Schedule I of the Wildlife (Protection) Act, 1972, which are at various stages of endangerment in the country. Equus hemionus khur and Mus platythrix, the two mammalian species of the region are endemic to India (Singh et. al., 1999).

During the last century, the Indian Wild Ass had a fairly wide distribution in the dry regions of northwestern India and west of Pakistan. The Wild Ass of Sind (E. h. khur) was hunted by Akbar, the Moghul Emperor on the bank of Sutlej River during the 16th century (Rao, 1957). The population also declined drastically between 1960 and 1969 and the species was included in Red Data Book as per IUCN Threat Criteria. The 1996 Red List of Threatened Animals has listed the sub species as Endangered according to its predicted population decline due to change in its area od occupancy, extent of occurence and change in quality of habitat (IUCN, 1996).

\section{Population Trend}

Ali (1946) estimated the population of Wild Ass in the Little Rann to be ranging between 3000 and 4000. In 1960, he put an estimate of about 2000 khurs in the Little Rann. In 1958 and 1960, an arthropod borne disease known as Surra, caused by Trypanosoma evansi took a heavy toll on Wild Asses (Gee, 1963). In November-December, 1961, some Wild Asses died due to an outbreak of South African horse sickness and a dwindled population of 870 individuals was estimated in 1962 (Gee, 1963). The Forest Department could record a figure of 362 Wild Asses in 1969 through an aerial survey. Since then, the Gujarat Forest Department has conducted four censuses and found that the population has increased consistently from 720 in April 1976 to 1989 in April 1983, 2072 in March, 1990 and 2839 in January 1999. The rate of increase was very slow from 1983 to 1990, probably due to severe drought for three years from 1985 to 1987 . The GEER Foundation estimated the population to be 2940 in November 1998.

The GEER Foundation conducted systematic counting of Wild Ass in and around the Little Rann up to the extent of 5 to $10 \mathrm{~km}$ from the boundary of the Sanctuary. A total of 2446 animals were counted, which did not include Wild Asses inhabiting the Great Rann and the outer zone beyond $10 \mathrm{~km}$. from the boundary. Partial counting was done in and around Khadir, Tragdi, Fatehgad Nada and other Bets in the Great Rann. Two herds were also counted near Nalsarovar and Dhandhuka-Dholera Highway in

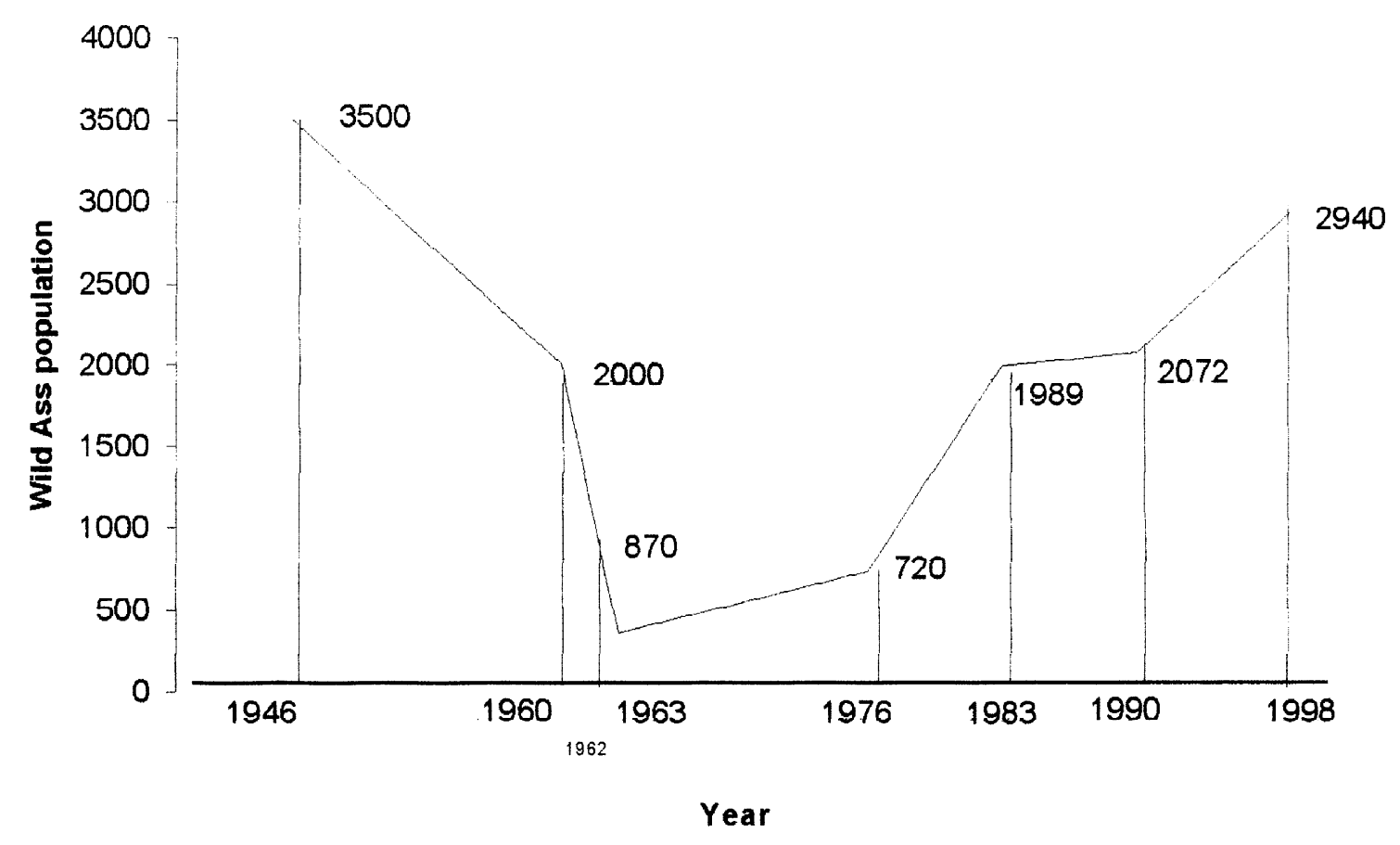

Figure 1. Trends in Wild Ass population during last 50 years in the Wild Ass Sanctuary. 
Ahmedabad District. On the basis of partial counting, reports of the forest officials and local people, it was estimated that over 490 Wild Asses dispersed in different parts of the Great Rann and outer areas beyond the distance of $10 \mathrm{~km}$. from the boundary of the Sanctuary in southern direction up to Dhandhuka (Bhal region). Thus, total population estimated by the Foundation in November, 1998 was 2940. The Little Rann and its surrounding zones did not experience severe drought as in 1987. This is one of the main reasons for consistent rise in population at a rate of 4.8 per cent per year (1990-1998). Wild Ass census conducted by the Forest Department in January 1999 ascertains the fact that population of the Indian Wild Ass reached about 28003000 .

\section{Population Distribution}

During the study 1780 Wild Asses in Dhrangadhra-Halwad region, 590 in Bhachau and 570 Wild Asses in Radhanpur region were estimated. Animals disperse far away from the boundary of the Sanctuary. Estimates from this study revealed that 390 to 490 Wild Asses stray beyond $10 \mathrm{~km}$. from the boundary of the Sanctuary. Census figure also indicated that about 70 per cent of the total population were found in Dhrangadhra/Halvad zone (eastern and southern fringes along with Rann, Bets and other areas near these fringes). Distribution pattern also revealed that the dispersed population is on the increase in new areas.

Distribution of Wild Ass population varied from season to season. As Rann submerges under knee deep water in monsoon, Wild Ass congregate in the fringe areas and on the Bets for four months. Three hundred and fifty eight Wild Asses congregated on Pung and neighbouring Bets during the monsoon in October, 1997 as herds from fringe areas move to the Bets during the breeding season. This number was recorded to be 415 in October, 1998 (Sanctuary Superintendent, pers. comm.). Dr. Ali (1946) has also the mentioned congregation of about 200 Wild Asses on Pung Bet. The Wild Asses face shortage of food and water on Bets and fringes during late winter and summer. Animals move to nearby villages and agriculture fields in the night for food and water and majority of them return to the Sanctuary by morning.

\section{Dispersal/Migration}

In 1976, the Wild Ass was restricted to the $5 \mathrm{~km}$. belt from the Sanctuary fringe (Shah, 1993). Animals migrated to areas beyond the distance of $10 \mathrm{~km}$. from the southern Rann fringe in 1989. South-eastern fringes are resource-rich (food and water) and maximum concentration of population and dispersal are observed in the peripheral villages in these fringes. People believed that Wild Asses started moving away from the Sanctuary after the drought in 1987. During the survey, 38 Wild Asses were seen on Khadir, Bangara and Kakidiya Bets, North-west of Khadir and a population of over 60 Wild Asses was estimated in and around Khadir Bet. Local people confirmed (November-
December, 1998) that a total of 53 Wild Asses were encountered in the part of the Sanctuary in the Great Rann (26 in Fatehgadh and 27 in Nada and other Bets near Rajasthan). Three Wild Asses ( 2 adults and 1 foal) were seen at the border in Rajasthan area, whereas a personnel of the BSF claimed that he saw a group of nine individuals in Rajasthan. This needs further confirmation. Foot-marks from Bela to Tuta on the Pakistan border indicated that animals visited Pakistan border, which was confirmed by the personnel of the Border Security Force (BSF).

Some Wild Asses had migrated out of the Sanctuary to Nalsarovar Bird Sanctuary and Bhal area. Sightings were also made near Dhandhuka-Dholera highway. A herd of 18 Wild Ass was counted near Kalatalav during the monsoon of 1998 and another group of six animals was seen near Devadthal during the same period. Wild Ass was also seen near Limbdi-Badodara highway. Wild Ass census and this survey established the fact that Wild Ass had migrated to Rajasthan and Pakistan border in the North, Dhandhuka-Dholera highway and south of LimbdiBagodara national highway in the South and Malia in the West.

\section{Population characteristics}

Mating and foaling in the Little Rann occur during monsoon, which is also a period of vegetation growth. During monsoon best nutrition is available, when females are lactating. This is also crucial time for the mares, as they have to overcome the stress and high energy cost of lactation. Both mating and foaling take place mainly in July to October. All births are single. The male foal weans at 1-2 years of age while the female continues to remain with mares for a longer period (Shah, 1993).

Out of the 2446 Wild Asses counted (637 males + 1402 females +407 foals) in and around the Little Rann, male:female ratio was 13:28. It is possible that some of the sub-adult males could not be distinguished from female and hence the male population was under-estimated. But this observation confirms the finding of Shah (1993) that male:female ratio is 1:2 in the Sanctuary. Foals constitute 16.6 per cent of the total population of the Wild Ass (young foal 10.5\%). When foals grow older than one year, it becomes difficult to distinguish them from the sub-adults. Thus some of the young ones of previous year could not be included in the list of the foals. In addition to 267 foals of current year in and around the Sanctuary, about a dozen foals of current year were seen in the outer zones in the Great Rann, Rajasthan and Bhal region. Thus, it would be correct to state that reproduction in the year 1998 was more than 275.

The largest herds of 89 Wild Asses at Visnagar, 86 at Koparni, 70 between Kanach and Thala Rann, 68 at Kidi, 61 at Degam Rann were counted. Of the total Wild Asses 60.4 per cent were recorded in groupsizeof small (3-20) to medium (21-40) and 36.3 per cent in very large group (41 to 90 ) size; 1.8 per cent of the Wild Asses, mainly males, were single whereas 1.5 per cent of 
the total population was in pairs (Singh et al, 1998).

\section{Population management}

The population of Wild Ass in the Little Rann needs to be well above 2500 as prescribed by the IUCN/SSC Equids Specialist Group (Duncan, 1992). Population of Wild Ass in and around the Sanctuary has already crossed this limit. Animals make regular raids in crop fields during winter and summer, causing resentment among farmers. They regularly complain and demonstrate against the loss of agricultural crops (cotton, wheat, gram etc.) caused by the Wild Ass and this problem is on the increase due to increase of Wild Ass, Nilgai and Wild Boar numbers close to the villages. Although Khur population has gradually increased and it may reach the level of the previous estimate given by Ali (1946) in the near future, it would be difficult to manage the entire population in the Sanctuary due to changed conditions. Original vegetation of grass/herbaceous land, sparse thorn forest of indigenous species is now invaded by Prosopis chilensis in many parts of the vegetation zone resulting in reduced availability of food. Disturbance as a result of salt preparation and transport, firing practice by the Indian Army, and livestock grazing by villagers have added to the factors responsible for habitat degradation. Hence it is difficult to maintain the original carrying capacity of the area, without improving the habitat and conservation status of the Sanctuary.

Growth trend of the last decade reveals that rate of this annual growth may be the upper limit of population increase in the Little Rann, due to long gestation period and other reproductive characteristics of the animal. If this trend continues and the area does not suffer from severe drought and disease, the population may exceed 4000 by $2010 \mathrm{AD}$. Trends also indicate that maximum increase of population would be near villages and dispersal zones. This will result in the migration of population to new areas of the Great Rann, Bhal and desert portion in Rajasthan. Bhal may support a moderate population of Wild Ass as manwildlife conflict would be serious when number becomes very high. Bets and fringe areas support good number of Wild Ass and there is scope to accommodate more Wild Ass in new areas in the Great Rann. Wild Ass has already entered Rajasthan border and hence, Thar Desert in Rajasthan may prove to be an important area to manage excess population. It is time to explore the possibility of development of Thar Desert near the border as alternative site for the Indian Wild Ass. As these animals were found in the desert historically, to allow natural process of dispersal of animals in the original habitat should not be a problem.

With increased population, some individuals can be considered for capture to ernhance the captive population in Indian zoos. Simultaneously, efforts should be made to find alternative sites for Wild Ass as part of long term conservation strategy.

\section{References}

Ali, S. (1946). Indian Wild Ass. J. Bombay nat. Hist. Soc. 3(46): 473. Alfred, J.R.B. and V.C. Agrawal (1996). The mammal diversity in the Indian desert. Gaps in research (eds. Ghosh Ak., Bargi Q.H. and Prakash I.). Scientific Publisher, Jodhpur.

Duncan, P. (1992). Zebras Asses and Horses: An action plan for the conservation of equids. IUCN/SSC, Equids Specialist Group, Gland, Switzerland $36 \mathrm{pp}$.

Gee, E.P. (1963). The Indian Wild Ass: A survey. J. Bombay nat. Hist. Soc. 60(3): 517-529.

IUCN (1996). 1996 IUCN Red List of Threatetend Animals. IUCN, Gland, Switzerland and Cambridge, U.K., 448 pp.

Khacher, L.K. (1994). Study on biosphere reserve in the Gulf of Kutch. CEE, Ahmedabad.

Rao, H. Srinivas (1957). History of our knowledge of the Indian fauna through ages. In: A century of natural history. J.C. Daniel (Ed.). BNHS, Mumbai, 70 pp.

Singh, H.S., R. Pravez, V.C. Soni, N.V. Shah and H.B. Patel (In press). Ecological study of the Wild Ass Sanctuary. Gujarat Ecological Education and Research Foundation, Gandhinagar.

Shah, N.V. (1993). The Eoclogy of Wild Ass in Little Rann of Kutch Ph.D. thesis. M.S. University, Vadodara, Gujarat State.

Shah, N.V. (In press). Study on mammals. Part of the ecological study of the Wild Ass Sanctuary. Report. GEER Foundation, Gandhinagar. 